\title{
Author Correction: A robust benchmark for detection of germline large deletions and insertions
}

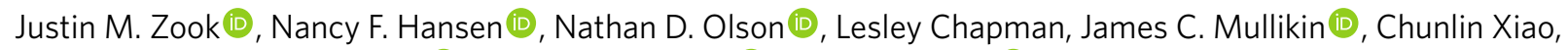
Stephen Sherry, Sergey Koren (1), Adam M. Phillippy @ , Paul C. Boutros (D), Sayed Mohammad E. Sahraeian,

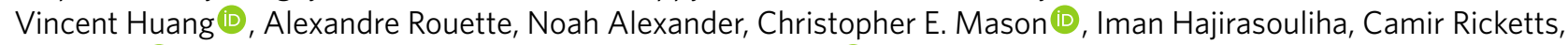
Joyce Lee (D), Rick Tearle, Ian T. Fiddes, Alvaro Martinez Barrio (1), Jeremiah Wala, Andrew Carroll, Noushin Ghaffari, Oscar L. Rodriguez, Ali Bashir, Shaun Jackman, John J. Farrell, Aaron M. Wenger, Can Alkan (D, Arda Soylev (1), Michael C. Schatz, Shilpa Garg, George Church (D), Tobias Marschall(1), Ken Chen (D), Xian Fan, Adam C. English, Jeffrey A. Rosenfeld (D), Weichen Zhou (D), Ryan E. Mills, Jay M. Sage, Jennifer R. Davis, Michael D. Kaiser, John S. Oliver, Anthony P. Catalano, Mark J. P. Chaisson, Noah Spies, Fritz J. Sedlazeck (1) and Marc Salit

Correction to: Nature Biotechnology https://doi.org/10.1038/s41587-020-0538-8, published online 15 June 2020.

In the version of this article initially published online, orange and black were switched in the legend to Fig. 5. The error has been corrected in the print, PDF and HTML versions of the article.

Published online: 22 July 2020

https://doi.org/10.1038/s41587-020-0640-y

(๑) The Author(s), under exclusive licence to Springer Nature America, Inc. 2020

\section{Publisher Correction: Modeling neural tube development by differentiation of human embryonic stem cells in a microfluidic WNT gradient}

Pedro Rifes (D), Marc Isaksson, Gaurav Singh Rathore, Patrick Aldrin-Kirk, Oliver Knights Møller (D), Guido Barzaghi, Julie Lee, Kristoffer Lihme Egerod, Dylan M. Rausch (D), Malin Parmar (D), Tune H. Pers, Thomas Laurell and Agnete Kirkeby (D)

Correction to: Nature Biotechnology https://doi.org/10.1038/s41587-020-0525-0, published online 25 May 2020.

In the version of this article initially published online, the data points and the text label FB/MB/HB in Fig. $3 \mathrm{~d}$ were shifted and mis-scaled relative to the dashed lines and other figure elements. The error has been corrected in the print, PDF and HTML versions of the article.

Published online: 11 June 2020

https://doi.org/10.1038/s41587-020-0590-4

(๑) The Author(s), under exclusive licence to Springer Nature America, Inc. 2020

\section{Publisher Correction: Antibody engineers seek optimal drug targeting TIGIT checkpoint} Elie Dolgin

Correction to: Nature Biotechnology https://doi.org/10.1038/s41587-020-0666-1, published online 4 September 2020.

The version of this article initially published said that initial phase 1 data from the domvanalimab trial are anticipated at the next SITC meeting in November. Instead, initial efficacy data from the domvanalimab trials are anticipated early next year. The error has been corrected in the PDF and HTML versions of the article.

Published online: 30 September 2020

https://doi.org/10.1038/s41587-020-0714-x

(c) The Author(s), under exclusive licence to Springer Nature America, Inc. 2020 